\title{
Domains and Directions in the Development of TBLT
}

Martin Bygate (Ed.). Amsterdam, the Netherlands: John Benjamins. 2015. Pp. xxiv +325 .

If one has to use a catchy word to capture the connection between the field of Second Language Acquisition (SLA) and Language Teaching (LT), the word "task" would be most likely to jump to mind. Since its initial proposals in the late 1980s, the concept has now blossomed into a distinct field of research, Task-Based Language Teaching (TBLT), which is often deemed to be a researched pedagogy that bridges a gap between SLA research and LT. Much of the development in TBLT is due to scholarly presentations and publications, particularly those by Long (1985, 2015), Skehan (1998), and Robinson (2001, 2011), among many others. The book Domains and Directions in the Development of TBLT is a comprehensive collection of selected plenary speeches delivered at biennial international conferences on TBLT from 2005 to 2013. Martin Bygate, editor of the book, introduces the book by highlighting the pivotal role of tasks and the research and educational relevance of TBLT, echoed throughout the entire book.

In chapter 1, TBLT: Building the Road as we Travel, Michael H. Long contextualizes TBLT in both general educational theory and instructed second language acquisition (ISLA). Informed by research findings on ISLA, Long highlights potential constraints that adult learners may encounter after having acquired their first language, such as learned attention and a weakened implicit learning capacity, which may prevent them from attending to form-meaningfunction mappings necessary for acquisition to occur. In view of such constraints, he argues that a purely focus on forms or focus on meaning approach would yield unsatisfactory learning results largely because the former leaves learners at their own means to assemble discrete linguistic items regardless of their developmental readiness whereas the latter predicates on the learner's strong implicit learning capacity, instance learning in particular, for picking up linguistic codes. To overcome these shortcomings, Long proposes a task-based approach with a focus on form, which allows for a temporary, reactive focus on problematic linguistic features triggered by communication breakdown. It is at these moments that learners are most likely to register and integrate such features into their developing interlanguage (IL) system. With this in mind, he elaborates on the procedures of a TBLT program, including needs analysis, syllabus design, materials development, methodology and pedagogy, assessment and program evaluation, with tasks being the core unit of analysis throughout.

In chapter 2, Thinking and Acting Programmatically in Task-Based Language Teaching, John M. Norris also traces the roots of TBLT to a general philosophy of education, emphasizing the importance of experiential learning and an educational environment encompassing all aspects of learning, design, situation and participant factors. However, he aptly points out that most current TBLT investigations, motivated primarily by theoretical concerns, focus narrowly on a handful of micro and discrete task-level phenomena such as the manipulation of task features on learning outcomes, which may shed little light on program-level phenomena and the educational relevance of TBLT in general. He thus advocates the use of program evaluation as a holistic, pragmatic, and programmatic inquiry approach to TBLT, which provides an epistemological and methodological footing that is more fitting for task-based education. He specifically explains that program evaluation confers advantages in providing an empirical, longitudinal, and diverse perspective into the dynamic and interrelated relationships between different elements of 
classroom learning environments and in establishing benchmarks for assessing leaning outcomes and program effectiveness that are generalizable to other educational contexts.

Lourdes Ortega and Marta Gonzalez-Lloret's chapter delineates the integration of technology into TBLT as well as the affordances and challenges of such technology, or computer-mediated communication (CMC), in promoting second language (L2) learning. Ortega and Gonzalez-Lloret argue that online interactions may instigate similar cognitive processes that are as conducive to L2 learning as face-to-face interaction. However, fundamental differences also exist, with online interaction typically featuring disrupted turn adjacency and delayed negotiation of meaning, which may result in little uptake of the target form. Nonetheless, tasks delivered via online interaction also afford unique advantages such as higher chance of selfrepair and the option of referring back to previous interactions during text-based CMC. More pertinently, the authors contend that the use of technology in TBLT may transform what counts as real-world authenticity and bring about heightened learner motivation. They also argue that given the unique characteristics of technology-mediated TBLT, what constitutes a complex task in the face-to-face interaction mode may differ from that in the CMC mode, hence the urgent need of reconsidering the construct of cognitive task complexity in technological environments and its impact on the learner's language performance.

The two ensuing chapters focus on two competing hypotheses that have motivated most theoretical and empirical research surrounding task complexity in TBLT to date, namely Peter Robinson's Cognition Hypothesis $(\mathrm{CH})$ and Peter Skehan's Limited Attention Capacity (LAC) Hypothesis. In his chapter, Robinson summarizes the fundamental pedagogical claim of the Cognition Hypothesis, which states that cognitive demands contributing to conceptual and cognitive processing complexity should be the sole criterion for sequencing tasks. His SSARC model stipulates that tasks simple on both the resource-dispersing and resource-directing dimensions should be performed first to allow learners to activate and draw on their simple, stable (SS) current IL system; cognitive demands should then be increased along the resourcedispersing dimension to promote automatic access (A) to the IL system; and finally, demands should be increased on both dimensions to foster restructuring $(\mathrm{R})$ and maximize complexity $(\mathrm{C})$ levels. Robinson also proposes a triadic componential framework, distinguishing task complexity from task conditions, which concern participation and participant variables, and task difficulty, which relates to learner ability and affective factors. He underscores the necessity of investigating the relationship among the three components in order to optimize task design and task-based instruction for improving L2 learning.

Twinned with Robinson's chapter, Skehan starts his chapter with five principles underlying the LAC Hypothesis, which includes limited working memory and attention; performance measured in terms of complexity, accuracy, lexis and fluency (CALF); task characteristics and conditions influencing task performance singly as well as in interaction; the relevance of the limited capacity hypothesis to the conceptualizing, formulizing, and articulating stages of Levelt's model of first language speaking; and the differential demands placed on those distinct stages by different task complexity variables. Skehan critiques the Cognition Hypothesis, particularly regarding the dissociation of task difficulty from the task itself and the attempt to represent task complexity through a list of variables divided into resource-dispersing and resource-directing dimensions. He maintains that those variables are not monolithic and may fall 
under either dimension depending on how the variables are manipulated. Skehan then provides a point-by-point comparison of the Cognition and LAC Hypotheses in terms of their underlying theoretical backgrounds and predications of task complexity variables on learner performance, acquisition, and development.

In their chapter Tasks, Experiential Learning, and Meaning Making Activities, Mohan, Slater, Beckett, and Tong broaden the scope of TBLT to content-based experiential learning involving socio-semantic meaning-making activities. Drawing on the central claim of Systemic Functional Linguistics (SFL) that human learning is essentially a meaning-making and semiotic process in social contexts, Mohan et al assert that L2 learners can develop their academic register of a particular discipline by progressing from discourse actions embedded in a particular context, to discourse reflections detached of the context, and eventually to more general reflections on newly acquired knowledge in relation to their own experience. To exemplify this proposal in action, Mohan et al provide examples of young children learning about magnetism and college students learning about marketing. They argue that such experimental tasks can serve as a sociosemantic activity of field and ideational meaning, and demonstrate how learners develop their academic discourse on magnetism and marketing while engaging in action and reflection discourses to develop a frame of meaning on the given topic and generalize the newly acquired knowledge to new scenarios. These examples provide concrete evidence on the employment of academic content tasks to support both language development and content learning.

Echoing Mohan et al. and John Norris, Heidi Byrnes also advocates situating task-based pedagogy in a functional theory of language represented by Systemic Functional Linguistics (SFL), the primary goal of which is to foster task-oriented curriculum development, thus reestablishing the educational interests of TBLT. The rationale underlying her proposal lies in the remarkably affinity of the task construct to the socio-semiotic potential of SFL, in that SFL provides a holistic and functional lens into oral and written discourses in which abundant natural lexicogrammatical resources are embedded, and task design can capitalize on those resources by engaging learners in meaning-making and language use. However, Byrnes argues that the adoption of such a functional perspective may encounter potential challenges from entrenched institutional practices, disciplinary constraints, and misunderstandings about what counts as a curriculum. To make it possible, Byrnes asserts that a task-based curriculum should accommodate all modalities, lay out a learning and developmental trajectory as manifested in different tasks from beginner to advanced levels, and seek out a theory that not only allows for meaning-oriented operationalization of the construct of task, but also enables educators to discern the learner's conceptual and linguistic development over the long haul.

While the preceding chapters focus primarily on the theoretical, pedagogical or curricular relevance of TBLT and tasks, the chapters that follow are concerned with tasks in action and how task users, instructors and learners in particular, perceive the effectiveness of tasks. In her chapter, Kim McDonough reports on 25 English instructors' perception on the use of collaborative tasks at a Thai university. Semi-structured interviews were conducted in Thai, English or a combination of both. Kim found that the instructors believed that collaborative tasks helped to orient the students toward task accomplishment and boost their confidence. However, the instructors also expressed concerns over the effectiveness of tasks in developing the students' grammatical competence and in eliciting interaction that is conducive to language learning. The 
concern was magnified in large classes where the instructors felt unable to monitor group interactions while providing appropriate feedback to each learner. The group dynamics were also influenced by the nature of tasks, group size, topic familiarity, and time pressure. To address those concerns, McDonough recommends modeling task performance and allowing for planning time during the pre-task stage, teaching learners communication strategies, and incorporating self-assessment to improve peer-peer interaction.

In view of scant published research on the actual use of tasks by practitioners and the lack of generalizability of laboratory-based task research to language classrooms, Rod Ellis proposes the use of micro-evaluation to gauge the effectiveness of a task in his chapter. To determine whether a task would unfold as intended, Ellis differentiates three evaluation criteria, namely a student-based motivation criterion, response-based performance criterion, and learning-based development criterion, with each requiring the collection of different data. He also specifies six steps for conducting a systematic evaluation of a task, including describing task materials and implementation procedures, determining the purpose of the micro-evaluation, specifying how to collect data, mapping out an evaluation plan, analyzing data, and summarizing findings of the evaluation. Applying this approach to teacher-researchers enrolled in his TBLT class, Ellis reveals remarkable variations in the instructors' selection and design of tasks as well as in the students' perceptions of the tasks, illustrating why the same task may transform into different activities once implemented in an actual classroom. He concludes the chapter by highlighting the potential of micro-evaluations in helping practitioners to determine the worthiness of a task within a local classroom context and in affording L2 researchers an ecological view of taskbased research.

Virginia Samuda provides yet another unique perspective into teachers' use of pedagogical tasks in the classroom. Rather than conceptualizing task as a stable and predictable construct, Samuda envisages it as a fluid, emergent, and evolving pedagogical tool mediated by the instructor during classroom use. To her, a task is a multidimensional plan in that it traverses from a designer's original plan to a teacher's lesson plan before instruction, to an online plan during instruction, and to a reformulated plan after instruction. The enactment of a task thus creates pedagogical spaces, if effectively designed and mediated by the instructor, may bring about beneficial learning outcomes. Samuda argues that such a framework of pedagogical tasks can document the evolving trajectory of a task as it is implemented in the classroom, which may enable the practitioner to achieve a principled understanding of task use and distill exemplary teacher classroom behaviors that may prove insightful for teacher training. To put her framework into practice, Samuda compares the use of one task by two different instructors, finding that while one instructor "re-tasked" the original workplan, the other "de-tasked" it by treating it as an exercise, thus showing the necessity of tracking the process of task implementation.

In the concluding chapter, Task-Based Language Education: From Theory to Practice ... and Back Again, Kris Van den Branden reiterates the importance of integrating both the teacher's as well as the learners' perceptions of actual task use in authentic classrooms into refining the guiding principles of task-based research. However, Van den Branden laments that existing definitions of tasks do not lend themselves to a pedagogical perspective of tasks that require language use in a classroom. Equally problematic is that most research in this regard attempts to predict learners' task performance by manipulating specific task design features 
instead of treating them as individual learners with disparate motivation, beliefs, and linguistic resources which may inevitably impact their task performance. This is evidenced in classroombased observation studies in Flanders, Belgium, where the same task transpired differently and brought about different affective and linguistic levels of learner engagement with the task. Therefore, in order for TBLT to be a researched pedagogy, Van den Branden argues that proponents of TBLT should factor in the teacher's practices and beliefs and more classroombased research should be conducted to capture tasks in action to enrich TBLT theory.

Together, the chapters in this book provide a comprehensive yet succinct representation of seminal work on TBLT, covering a variety of key topics such as the educational and philosophical foundations of TBLT (Bygate, Long, Norris, and Byrnes), its relevance to program and curriculum design and program evaluation (Long, Norris, and Byrnes), the psycholinguistic perspective of task complexity (Robinson and Skehan), technology-mediated TBLT (Ortega \& Gonzalez-Lloret), a functional approach to TBLT (Mohan et al. and Byrnes), and teachers' and learners' perceptions of task use in the classroom (McDonough, Ellis, Samuda and Van den Branden). The inclusion of such wide-ranging topics makes the book an interesting read for seasoned scholars who wish to delve deeper into the various issues addressed therein, and to get a sense of where the field is heading. The book would also serve as an ideal course book for graduate students in applied linguistics programs to gain an insider's perspective on the development of TBLT.

\section{HAIMEI SUN}

Teachers College, Columbia University

\section{REFERENCES}

Long, M. H. (1985). A role for instruction in second language acquisition: Task-based language teaching. In K. Hyltenstam \& M. Pienemann (Eds.), Modeling and assessing second language acquisition (pp. 77-99). Clevedon, Avon: Multilingual Matters.

Long, M. (2015). Second language acquisition and task-based language teaching. Oxford: Wiley-Blackwell.

Robinson, P. (2001). Task complexity, task difficulty, and task production: Exploring interactions in a componential framework. Applied Linguistics, 22(1), 27-57.

Robinson, P. (Ed.). (2011). Second language task complexity: Researching the cognition hypothesis of language learning and performance (Vol. 2). Amsterdam, the Netherlands: John Benjamins Publishing.

Skehan, P. (1998). A cognitive approach to language learning. Oxford: Oxford University Press. 